\title{
Attrition Revisited: Identifying the Problem and Its Solutions
}

\author{
Janice H. Laurence, Jennifer Naughton, and Dickie A. Harris \\ Human Resources Research Organization
}

Selection and Assignment Research Unit Michael G. Rumsey, Chief

January 1996

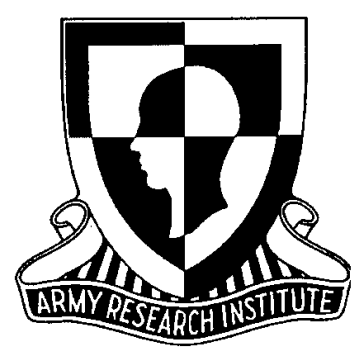

United States Army

Research Institute for the Behavioral and Social Sciences

Approved for public release; distribution is unlimited. 


\title{
U.S. ARMY RESEARCH INSTITUTE FOR THE BEHAVIORAL AND SOCIAL SCIENCES
}

\author{
A Field Operating Agency Under the Jurisdiction \\ of the Deputy Chief of Staff for Personnel
}

EDGAR M. JOHNSON

Director

\author{
Research accomplished under contract \\ for the Department of the Army \\ Human Resources Research Organization \\ Technical review by \\ Frances Grafton \\ Clinton B. Walker
}

\section{NOTICES}

DISTRIBUTION: This report has been cleared for release to the Defense Technical Information Center (DTIC) to comply with regulatory requirements. It has been given no primary distribution other than to DTIC and will be available only through DTIC or the National Technical Information Service (NTIS).

FINAL DISPOSITION: This report may be destroyed when it is no longer needed. Please do not return it to the U.S. Army Research Institute for the Behavioral and Social Sciences.

NOTE: The views, opinions, and findings in this report are those of the author(s) and should not be construed as an official Department of the Army position, policy, or decision, unless so designated by other authorized documents. 


\section{REPORT DOCUMENTATION PAGE}

\begin{tabular}{|l|l|}
\hline $\begin{array}{l}\text { 1. REPORT DATE } \\
\text { 1996, January }\end{array}$ & $\begin{array}{l}\text { 2. REPORT TYPE } \\
\text { Final }\end{array}$ \\
\hline
\end{tabular}

4. TITLE AND SUBTITLE

Attrition Revisited: Identifying the Problem and Its Solutions

6. $A \cup T H O R(S)$

Janice H. Laurence, Jennifer Naughton, and Dickie A. Harris
3. DATES COVERED (from. .. to)

July 1994-November 1994

5a. CONTRACT OR GRANT NUMBER

MDA903-93-D-0032

5b. PROGRAM ELEMENT NUMBER

$0603007 \mathrm{~A}$

5c. PROJECT NUMBER

A792

5d. TASK NUMBER

1212

5e. WORK UNIT NUMBER

$\mathrm{C} 05$

8. PERFORMING ORGANIZATION REPORT NUMBER

FR-PRD-95-01

Alexandria, VA 22314

9. SPONSORING/MONITORING AGENCY NAME(S) AND ADDRESS(ES)

U.S. Army Research Institute for the Behavioral and Social Sciences

ATTN: PERI-RS

5001 Eisenhower Avenue

Alexandria, VA 22333-5600

Research Note 96-20

\section{DISTRIBUTION/AVAILABILITY STATEMENT}

Approved for public release; distribution is unlimited.

13. SUPPLEMENTARY NOTES

COR: Clinton B. Walker

14. ABSTRACT (Maximum 200 words):

This report highlights the known and suggested causes, correlated, and contributors to first-term enlisted attrition. Personal characteristics such as education credential, aptitude, gender, and age are discussed first followed by a description of organizational and situational influences. Better coordinated multivariate selection approaches to attrition are suggested as are realistic previews of military life. A pivotal factor in attrition is its management/policy control at various levels. This aspect of attrition must be understood before other reduction strategies are introduced.

15. SUBJECT TERMS

Attrition Selection Classification $\quad$ Enlisted personnel

\begin{tabular}{|c|c|c|c|c|c|}
\hline \multicolumn{3}{|c|}{ SECURITY CLASSIFICATION OF } & \multirow{2}{*}{$\begin{array}{l}\text { 19. LIMITATION OF } \\
\text { ABSTRACT } \\
\text { Unlimited }\end{array}$} & \multirow{2}{*}{$\begin{array}{l}\text { 20. NUMBER } \\
\text { OF PAGES } \\
28\end{array}$} & \multirow{2}{*}{$\begin{array}{l}\text { 21. RESPONSIBLE PERSON } \\
\text { (Name and Telephone Number) }\end{array}$} \\
\hline $\begin{array}{l}\text { 16. REPORT } \\
\text { Unclassified }\end{array}$ & $\begin{array}{l}\text { 17. ABSTRACT } \\
\text { Unclassified }\end{array}$ & $\begin{array}{l}\text { 18. THIS PAGE } \\
\text { Unclassified }\end{array}$ & & & \\
\hline
\end{tabular}


ATTRITION REVISITED: IDENTIFYING THE PROBLEM AND ITS SOLUTIONS

CONTENTS

Page

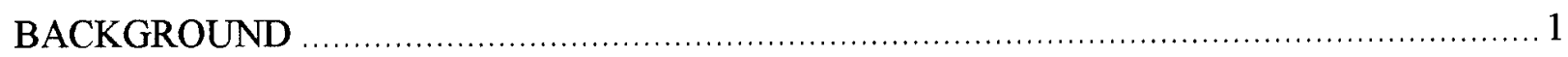

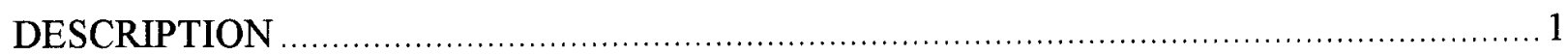

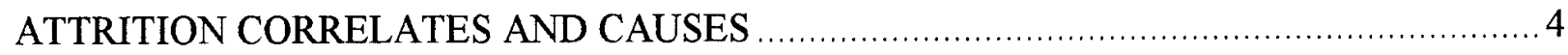

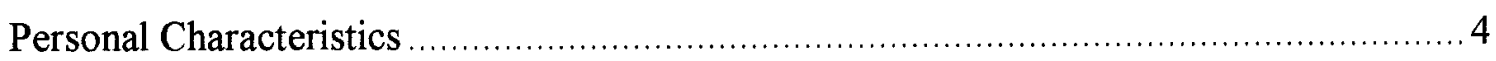

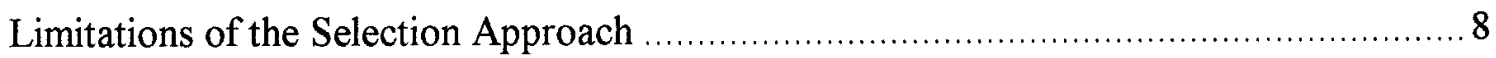

Organizational and Situational Influences ........................................................ 10

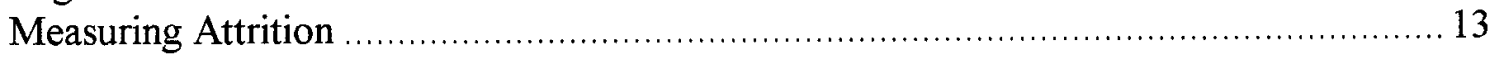

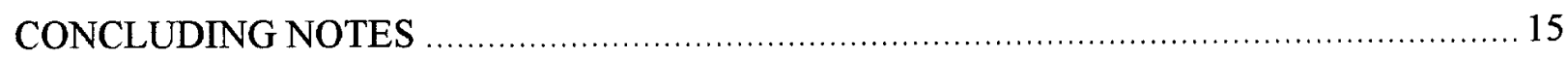

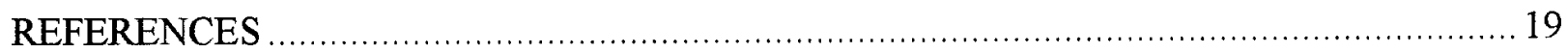




\section{Attrition Revisited: Identifying the Problem and Its Solutions}

\section{Background}

Enlisted attrition is succinctly defined as the failure to complete the contracted first enlistment term. Unfortunately, the simplicity of this performance measure is superficial; attrition is actually quite complicated. Such departures from the military may be voluntary, involuntary and/or under pejorative or nonpejorative circumstances. Furthermore, attrition rates have been shown to covary with numerous individual and group characteristics as well as with organizational and job characteristics and perceptions. Studies have also suggested that the magnitude of attrition is responsive to explicit and implicit administrative contingencies. All of these factors have been implicated as contributing to the incidence and timing of attrition.

This report is not meant to be an exhaustive review of the extant literature regarding enlisted attrition. Rather, typical and critical findings are highlighted to provide the reader with a description of the phenomenon of attrition. The review will recount its known and suggested causes, correlates, and contributing factors. These factors are first discussed separately and then integrated in concluding notes. Also, critical research and potential remedies for this seemingly untractable problem are suggested.

\section{Description}

For years, attrition, the military's version of personnel turnover, during the first enlistment term has served as a favorite performance measure because of its apparent simplicity. Though completion of the contracted term may appear to be a simple, foolproof, and reliable criterion, many different behaviors may contribute to a soldier's exodus.

The criterion of attrition is routinely captured and coded in personnel databases. A standardized Interservice Separation Code (ISC) has been constructed for use across Services. There are eight broad ISCs within which personnel losses are categorized:

- Release from Active Service

- Medical Disqualifications

- Dependency or Hardship

- Death

- Entry into Officer Programs

- Retirement (Other than Medical)

- Failure to Meet Minimum Behavioral or Performance Criteria

- Other Separations or Discharges 
The first category is indicative of releases following a successful term and thus is the antithesis of attrition or the positive aspect of this performance criterion. Losses due to death, entry into officer programs, and retirement, while coded as withdrawals from the enlisted ranks, are relatively infrequent and nonpejorative; thus they are not generally considered within the realm or criterion space of attrition. Attrition is defined according to the criteria of the remaining pejorative categories (i.e., medical disqualifications; dependency or hardship; failure to meet minimum behavioral or performance criteria; and other).

Around one-third of an entering accession cohort separates before completing three years of an obligated term and by far, most attrition (approximately 75 to 80 percent) falls within the bounds of failure to meet minimum behavioral or performance criteria (Flyer \& Elster, 1983; Klein \& Martin, 1991; Laurence 1984). Unfortunately, this failure category includes almost 30 more specific reasons for separation, including character or behavior disorder, motivational problems, inaptitude, alcoholism, use of drugs, discreditable incidents, misconduct, unsuitability, pattern of minor disciplinary infractions, homosexuality, fraudulent entry, trainee and expeditious discharge among others. Half of the remaining instances of attrition appear to be medically related. Although classifying medical disqualifications, dependency or hardship, and other separations or discharges as pejorative attrition may seem harsh, anecdotal evidence has it that there is considerable flexibility as to exactly what constitutes grounds for discharge, how a discharge is coded, and the ease with which a discharge is given (Foch \& King, 1977; General Accounting Office, 1980; Walker, White, \& Schroyer, 1989). Basically, a person who seeks to sever the enlistment contract can do so by displaying a pattern of disciplinary infractions tantamount to openly requesting a discharge. The attrition code need not necessarily match the cause. For example, medical attrition has been noted to rise when attrition for behavioral causes is capped (Walker et al., 1989; Grafton, personal communication, 1994).

The lumping together of qualitatively different causes of attrition and/or the poor correspondence between ISCs and actual reasons may work against the prediction and control of attrition (Dempsey \& Waters, 1989; Klein, Hawes-Dawson, \& Martin, 1991). It is difficult to determine from administrative records whether attrition was truly voluntary or involuntary, a result of medical or physical unfitness as opposed to behavioral delinquency of some sort, or the result of innocuous, unforseen, or random events. Nondescript labels such as Entry-Level Separation Program or expeditious discharge may be an administratively efficient means of separating personnel, but they are not terribly descriptive. Though the topography may be the same--leaving service prematurely--a better understanding of the underlying criterion is vital for progress towards solutions. An analysis of causes for attrition, as ascertained via hard-copy personnel records of samples of the FY 1979 and 1985 cohorts, indicated that the four most prevalent causes were work/duty, training, minor offenses, and mental health problems (Klein, et al., 1991). Furthermore, these researchers determined that the majority of early separatees had two or more contributing causes. Work/duty problems 
were frequently accompanied by other factors (e.g., alcohol abuse). Although the various separation codes may represent instances of what Hogan and Hogan (1989) term organizational delinquency, the lack of consistent coding and uncertainties regarding the correspondence between cause and code prevent the certainty of such a conclusion.

Another aspect that contributes to the conundrum of attrition is timing. Attrition does not occur uniformly throughout the first term. Instead attrition is disproportionatly high within the first six months of enlistment (Buddin, 1984). Approximately 30 percent of attrition occurs during this interval (Klein, et al., 1991). Almost half of first term attrition occurs within the first 12 months of service (General Accounting Office, 1980). The other half occurs over a 24 or 36 month period. Basically, attrition is noted within three distinct periods of military life: 1) during basic training; 2) during skill training; and 3 ) in the field or on the job, with potentially different factors coming into play during these periods (Buddin, 1984). It has been suggested that types of attrition covary with the timing of attrition (e.g.,physical fitness and mental health, particularly emotional instability and inability to adjust, are early problems whereas alcohol, drug, and criminal offenses increase in prevalence) (Klein, et al., 1991). The type and timing of attrition are important considerations for prediction and control.

Attrition has commanded attention because of its cost in addition to its apparent ease of measurement. Several years ago, the U.S. General Accounting Office estimated the cost of attrition at $\$ 11,700$ for each person who leaves service prematurely (General Accounting Office, 1979). Such cost estimates include lost investment in training, higher recruiting and salary costs for obtaining replacements, veterans' benefits, and unemployment compensation. A more recent estimate of the cost of first-term adverse attrition across all Services was put at $\$ 200$ million per year using a 1989 dollar metric (Klein, et al., 1991).

While attrition is hardly a new problem for the military, the advent of the AllVolunteer Force (AVF) in 1973 was accompanied by a growth in attrition of approximately 10 percent (Segal, 1981). By 1977, first-term attrition had emerged as one of the military's most serious and costly problems (Sheridan \& Monaghan, 1980). The increase in attrition has been attributed to many variables, including longer enlistment terms and the implementation of trainee and expeditious discharge policies for the rapid administrative discharge of marginal recruits. The increasing incidence and costs of attrition are alarming; however, current cost estimates are inflated. The costs of forcing recalcitrant and/or marginally performing recruits to remain on duty are difficult to estimate and thus have not been weighed in the cost equation. Attrition costs vary by job and other factors, thus it is unwise to use the mean cost for every person who separates, regardless of circumstance. Furthermore, there is an implicit assumption in the cost accounting of attrition that all early departures are "bad," with no return on investment, that counterattrition programs are cost free or close to it, and that the attrition rate should be zero. It is naive to expect no attrition--for no selection and classification system is perfect. Research aimed at determining the cost-effectiveness of 
expeditious discharges and the appropriate range of attrition is needed to quell concerns over the apparent excessive cost of attrition. Attrition is but one component of performance.

\section{Attrition Correlates and Causes}

Personal Characteristics. Despite the multidimensionality of attrition and the lack of a complete understanding of this criterion, the search for causes and correlates has proceeded. The typical research paradigm has been to investigate the relationship between personal characteristics and completion of the enlistment term. Regression analyses have uncovered a host of variables, including age, race, AFQT score, gender, marital status, and education credential. The best single predictor of attrition is the latter--education credential (Laurence, 1987).

Time and again, studies have found higher attrition rates for non-high school graduates than for high school graduates (Cheatham, 1978; Hand, Griffeth, \& Mobley, 1977, Elster \& Flyer, 1982; Flyer, 1963; Laurence, 1984, 1987; Smith \& Kendall, 1980). The differences in attrition rates by education credential are substantial. It is estimated that a high school diploma graduate has almost an 80 percent probability of completing three years, whereas the probability for nongraduates is around 60 percent (Department of Defense, 1981; Laurence, 1987). For those with alternative education credentials (e.g., GED), the attrition rates more closely resemble the non-graduate group than high school diploma graduates (Elster \& Flyer, 1982; Laurence, 1987). Although the strength of the relationship varies, differential attrition rates by educational level is a consistently held finding across all four Services, race, and gender. This relationship has also been found to hold across different cultures, specifically the United Kingdom, Australia, and Canada (Sinaiko \& Scheflen, 1980, 1982).

The reasons why high school graduates are less likely to attrit are unclear. It has been postulated that noncognitive factors account for most of the diploma's predictiveness because differential attrition rates between graduates and non graduates are persistent even after factors such as aptitude have been controlled (Laurence, 1984, 1987). Most likely, the personal skills and attributes that enable students to complete high school also enable them to complete their first term. A high school diploma signifies attributes such as maturity, perseverance, and tolerance for rules and regulations, which are true correlates for success in the military (Laurence, 1984). In order to graduate, students must learn to cooperate with their instructors and to get along with their peers. A high school degree not only represents a certain level of academic success, but more importantly, a degree of discipline (Cheatham, 1978). Despite its significance, the efficiency of education level to predict attrition remains limited since numerically more graduates than nongraduates attrit (Laurence, 1987). 
Aptitude, namely Armed Forces Qualification Test (AFQT) score, together with education credential serves as a quality barometer. That is, high school diploma graduates scoring in the upper end of the AFQT distribution (Categories I through IIIA) are preferred enlistment candidates. Diploma graduates are sought because they are less likely to attrit. Higher AFQT recruits show promise of better training and job performance (Campbell \& Zook, 1990). Non-graduate recruits, when enlisted, are required to achieve higher scores on the AFQT than graduates. Such policies seek to ensure that the more attrition-prone nongraduates have the compensating factor of a high aptitude level and thus greater assignment flexibility. Unfortunately, if aptitude alone is considered in the assignment process, this will increase the cost of attrition for high aptitude nongraduates because such high scorers are likely to be assigned to MOS with relatively high training costs.

The literature suggests that enlistees with higher AFQT scores are somewhat less likely to attrit than those in lower aptitude categories (Flyer \& Elster, 1983; Laurence, 1984, 1987). Overall, a weak inverse relationship has been found between AFQT category and attrition (Klein \& Martin, 1991) and, according to Antel, Hosek, and Peterson (1987), a 25 point increase in AFQT score would only decrease attrition by 3 percentage points. AFQT is a somewhat better predictor of attrition for high school graduates than for non-graduates. Among non-high school graduates, there is a nonmonotonic, inverse relationship between attrition and AFQT score with Category IVs showing a slightly lower attrition rate than comparable enlistees in Category IIIB (Elster \& Flyer, 1982). There may be a difference in the predictive efficiency of AFQT scores for different racial/ethnic groups as well. Specifically, Elster and Flyer (1982) found AFQT scores to be.a better predictor for whites than blacks. The findings that AFQT is less predictive for nongraduates and minorities is confounded by the narrower range of AFQT scores within these groups than among graduates and whites.

Attrition rates by gender indicate that women are more likely to leave the Military before the end of their term than are men (Flyer \& Elster, 1983). In general, women are significantly more likely to be absent or attrit for medical reasons, whereas men are more likely to attrit for disciplinary-related reasons (Olsen \& Stumpf, 1978). Among medical reasons for women to separate, pregnancy was frequently cited. Flyer and Elster (1983) reported that the difference in attrition between males and females would be virtually equal if pregnancy discharges were excluded from analysis.

Determining true attrition differences between men and women in uniform is clouded by previous policies (pre-1975) which led to the automatic discharge of pregnant military members. Since 1975, pregnancy is not an automatic cause for dismissal, however, separation policies are lenient with regard to pregnancy and may even encourage women to separate early.

Age has also been found to be related to attrition, albeit the relationship is not especially strong. There is some evidence that older recruits are more likely to leave for medical causes whereas younger recruits are more likely to leave for behavioral causes. 
The literature suggests a difference in this relationship for males and females. For males, a curvilinear relationship between age and attrition has been noted. Most literature supports the finding that loss rates are highest for 17 year olds and lowest for 18 and 19 year olds (Flyer and Elster, 1983; Kantor \& Guinn, 1975; Hand, Griffeth, and Mobley, 1977; Plag, 1971). There is some disagreement regarding the age at which an enlistee should be considered a poor attrition risk. Matthews (1977) suggested that 21 year olds are poor attrition risks, whereas Lockman (1975) found that persons 20 and older were more likely to separate prematurely. The high rates of attrition at the youngest age of entry suggests that a year of post-high school experience is useful in reducing attrition (Black \& Fraker, 1984). For older recruits, too much of a gap between high school and enlistment may be a signal of societal maladaption.

More equivocal findings have also been noted with regard to the relationship between race and attrition. For instance, Lockman found that the attrition rates were higher for minorities than for non-minorities, whereas Black and Fraker as well as Klein and Martin (1991), revealed no significant difference in attrition rates among blacks and non blacks after controlling for several key characteristics. By contrast again, research by Flyer and Elster (1983) found that except in the Army, male black enlistees have higher attrition rates than non-blacks after controlling for education. Flyer and Elster also found that for women, blacks had lower attrition rates and black women were less frequently discharged for pregnancy. On the other hand, Matthews (1977) found that whites were more likely to attrit than blacks. Cooke and Quester (1988) attempted to determine attrition patterns by race. They concluded that members of racial or ethnic minority groups were more likely to have disciplinary actions than whites, but that whites were more likely to. have administrative discharges as an alternative to court martialing (Beusse, 1977). Whether these findings are due to behavior differences between racial/ethnic groups or differences (and perhaps biases) in coding is uncertain.

The literature is fairly consistent in indicating that married male and female enlistees are more likely to attrit than single enlistees (Flyer \& Elster, 1983; Mobley, Hand, Baker, \& Meglino, 1978), though the relationship is weak (Klein \& Martin, 1991). However, Flyer and Elster indicate that there are a few exceptions to this pattern. According to their research, for black female high school graduates there is no significant difference in the attrition rates between married and single recruits. In addition, they report that for both male and female Air Force enlistees, marriage is not significantly related to attrition among high school graduates, and that attrition rates for non-graduate married recruits is actually lower than for single recruits.

The literature regarding the presence or absence of dependents related to attrition is not especially plentiful. Limited evidence indicates that having no dependents significantly increases the probability of serving out a full term (Smith, \& Kendall, 1980). As with the findings regarding attrition and marital status, there are inconsistencies regarding the relationship between the presence of dependents and attrition. A simple univariate analysis no doubt confounds age, pay grade and other in-service variables with 
family background. The Army should not rush to institute anti-marriage, pro-dependent policies not only because of inconsistent and complex relationships with attrition but also because family issues and their effects on retention are something that the Army must deal with in a positive manner rather than trying (and failing) to get rid of the issues.

Geographic region of origin has also been considered in relation to attrition in a few studies. The scant evidence suggests that home of record is not a very telling variable but varies by race in that many geographic areas with high attrition rates for blacks are not the same for non-blacks, and vice versa. However, it should be noted, that the inclusion of geographic variables in the prediction of attrition seems unpractical at best and extremely confounded with demographics.

A less innocuous correlate of attrition is moral character. That is, military recruits with offense histories related to such things as criminal behavior, sexual conduct, and substance abuse enlisted on a moral waiver are more likely to leave service prematurely (Klein \& Martin, 1991; Means, 1983). The attenuated relationship between waiver status and attrition (and the stronger relationship for graduates) is influenced by accession policies that ensure that waiver holders are otherwise a more select group (Means, 1983).

Although, for the most part, background variables have been considered singly or within simple cross tabulations, multi-variable biographical questionnaires have shown enhanced prediction of attrition over single variable models. Items arranged in a multiple choice format pertaining to background characteristics and behaviors, such as high school academic performance, school behaviors and attitudes, and work history, have shown promise at least in experimental settings (Laurence \& Waters, 1993). Such biodata inventories have not supplanted or even supplemented selection based on education credential because of the valid fear that such screens may become unstable or otherwise show a marked decrease in validity. A proposed multivariate alternative to biodata is represented by the Army's Assessment of Background and Life Experiences (ABLE)--a rationally scored temperament inventory. ABLE's Adjustment and Dependability scales have been shown to be valid predictors of attrition in a nonoperational setting (White, Nord, Mael, \& Young, 1993). Because temperament measures are thought to be particularly susceptible to response distortion (faking and coaching), biodata analogues to ABLE, comprising objective and verifiable items, have been investigated and appear promising. Despite preliminary work on alternate forms and a score monitoring program to retard compromise, neither biodata nor temperament inventories are currently used for attrition screening because of technical and practical reasons relating to concerns over faking and coaching. Because of promising experimental findings, biodata deserves a solid operational test accompanied by compromise reduction strategies. If not in a selection system, biodata/temperament should at least be considered for implementation in a classification mode to steer recruits with a particular high risk of attrition for certain MOS away from those MOS. 
So far, instead of biodata, a compensatory screening model (CSM) approach to reducing attrition has been applied. Such a model is based upon personal characteristics such as education credential and age, cognitive ability, and educational attainment (or years of education) under the assumption that personal characteristics positively associated with attrition could be compensated for by other variables that are negatively associated with attrition (Dempsey, Laurence, Waters, \& McBride, 1991). As of yet, a CSM has not been operationally implemented except by the Navy in a trial administration for use with non-graduate recruits only (Edwards, McBride, Waters, \& Laurence, 1993).

A CSM approach to attrition is not altogether new. The Navy has used a combination of predictors such as AFQT score, education, and age to compute Success Chances for Recruits Entering the Navy (SCREEN) and before that the Odds for Effectiveness (OFE). The Air Force also previously experimented with a compensatory approach to screening initial "failures" and found that such an approach provided incremental validity, though not to the degree that biodata might have afforded (see Laurence \& Gribben, 1990).

Limitations of the Selection Approach. The primary tool used to combat attrition has been the application of so-called education differentials. That is, regular high school diploma graduates are the preferred enlistment candidates, with alternative credential holders and those without credentials enlisted sparingly and required to meet higher minimum aptitude scores when and if enlisted. Recently it has been bemoaned that despite the rise in high school graduate proportions among accession cohorts, attrition has not declined precipitously (General Accounting Office, 1994).

Despite the facts that (1) the credential has been shown to be the best single predictor of attrition and (2) the percentage of regular diploma holders has increased during the past decade, attrition rates remain around 30 percent. Eitelberg (1993) examined attrition for 1973 through 1988 accession cohorts and showed the first-term (over a four year period) attrition rate for the Army to range from 31 percent in FY 1973 to 38 percent in 1977. Klein and Martin (1991), using FY 1985 cohort data, estimated that attrition would decrease by only 4 percentage points (e.g., from $20 \%$ to $16 \%$ ) if the Army were to enlist only I-IIIA high school diploma graduates not needing a moral waiver. This is because education credential, while the best single predictor, is not overwhelmingly related to attrition. Put another way, the predictive efficiency of educational status is limited. Further, although nongraduates indeed have higher attrition rates, there have always been many more graduates than nongraduates, thus the former are numerically the largest component of attrition. Furthermore, accession policies may partially cancel each other out. Lower AFQT cutting scores are applied to graduates and moral waivers are more likely to be applied to otherwise high quality accessions. As mentioned above, there is a relationship (albeit a small one) of attrition to both waiver status and AFQT score (in the expected direction), and the Services have become increasingly gender-integrated and family oriented. These interactions and 
cancellations among personal characteristics are discussed with the hopes of alerting policy makers to the problems of and difficulties in controlling attrition. Women and families are a vital part of the military despite the fact that at least temporarily these characteristics contribute to higher attrition statistics.

There are other reasons why attrition hasn't come down drastically in response to increases in the percentage of high school diploma graduates among recruits. It is very plausible that the association between diploma status and factors such as perseverance and dependability may have been watered down over the years. Students are passed along despite academic and motivational deficits. Thus, earning a regular diploma doesn't take as much discipline as it used to. Similarly, anecdotal evidence suggests that along with a cognitive ability decline, our nation's youth may have experienced a physical fitness decline that may have a bearing on attrition. It may not be farfetched to ponder the impact of increasing violence and other social or antisocial trends among youth. Singly, none of these factors may be severe, but together they can detract from attrition prediction.

There is little doubt that selection and training, not to mention an enlistment contract, contribute to the generally lower rate of attrition among youth in the military compared to turnover among 18 to 23 year old youth in the civilian employment sector (Waite \& Berryman, 1985). For example, after one year about $57 \%$ of young men and $55 \%$ of young women are reported to leave an employer whereas the figures after a years' time for the military are reported as $22 \%$ and $21 \%$ (including contract end), respectively, for men and women (Waite \& Berryman, 1985). At about 50\%, college drop out rates also top enlisted attrition (Goodstadt \& Glickman, 1975). However, exclusive reliance on education credentials, particularly without considering other personal characteristics, is not enough to curb attrition drastically. This is not meant to suggest that other personnel characteristics such as gender and geography be used in the selection equation to limit enlistment. After all, equity and diversity, not to mention meeting strength requirements are important goals in their own right. Further, it is not realistic to assume that attrition can be eliminated completely. Just the same, small reductions in attrition from the application of selection screens can mean large cost savings (White, Nord, Mael, \& Young, 1993; Laurence, 1987).

Aside from the failure to recognize the multivariate, interactive relationship of personal characteristics to attrition and the impact of the supply of personnel on selection vigor, the institutionalization of "percent high school diploma graduate" as a quality indicator is also problematic. Diploma status is easily quantified and understood. Perhaps for this reason it has been reified to the point that Service policymakers and even Congress have come to expect and demand high proportions of high school graduates in accession cohorts. Alternative selection strategies, when conceptualized, are often, if not exclusively restricted to the demand-constrained non-graduates, thus reducing the effectiveness of potential attrition screens. For example, the Navy's trial CSM is applied only to non-graduates despite the fact that there is evidence that its 
validity would be higher for graduates. The rationale for such an approach is to avoid reducing the supply of "quality." The utility of applying extra screening to such demand constrained groups as opposed to all applicants is questionable. It is time to consider new or additional definitions of quality.

The almost exclusive reliance on a personnel screening approach leaves much to be desired. However, such an approach need not be eschewed but should be expanded. It is important to understand the criterion and its interactions with personal characteristics (Seibold, 1981). Furthermore, it would behoove the Army to know not just who leaves but why and when. By obtaining the answers to these additional questions, prevention and rehabilitation or remediation strategies can join forces with a selection approach. The next section discusses environmental correlates which begin to address issues beyond "who" attrites.

Organizational and Situational Influences. In addition to personal characteristics, the impact of the organization and environment on the causes and rates of attrition are important to consider. For example, studies have found differences in attrition rates between Services and between jobs within Services (Fernandez, 1985; Finstuen \& Alley, 1983; Rosenthal \& Laurence, 1988), as well as with different leadership styles (Department of the Army, 1984; Novaco, Sarason, Cook, Robinson, \& Cunningham, 1979). In addition, wide variations in attrition rates have been found across training units (Buddin, 1988; Trent, personal communication, 1994; U.S. Army, 1984).

The change in organizational climate associated with the military's transformation from reliance on the draft to recruiting solely volunteers has been implicated as a factor contributing to attrition. In contrast to hardline disciplinary policies in effect under a draft environment, easy and early discharges for recalcitrant personnel are favored for volunteer recruits. Without a draft available to help procure personnel, persuasion, enticements, and opportunities are offered to lure prospective recruits. Harsh discipline and coercion are feared to detract from recruiting. However, despite amenities such as higher pay, education incentives, beer machines in the barracks, fast food, less kitchen patrol (KP), and the elimination of rock painting, disillusionment or dissatisfaction with military service remains and personal freedom is still constrained. Although it's impractical to completely alter the military environment and it's doubtful that complaints would be eliminated with organizational change, particularly distasteful features should be identified and either modified, if possible, or, if essential, their reasons for existence should be explained to soldiers.

According to Boesel and Johnson's (1984) review of the scant organizational literature, incentives and disincentives are more likely to be associated with the failure to reenlist, whereas mismatches between the individual and service life account more for attrition. Interviews with recruits and exiting members have suggested however, that recruits undervalue compensation--failing to appreciate the value of allowances and non- 
monetary benefits. If such misperceptions meet with perceived or actual employment alternatives, turnover is likely (Stolzenberg \& Winkler, 1983). More broadly, unrealistic expectations are seen to play a role in attrition--particularly early attrition (Greenberg, Murphy, \& McConeghy, 1972; Stolzenberg \& Winkler, 1983; Youngblood, Laughlin, Mobley, \& Meglino, 1980). A picture emerges of impulsive youth with limited labor market knowledge reacting negatively to regimentation and discipline for seemingly trivial matters as well as unexpected physical exertion and fitness requirements.

Participation in the Delayed Entry Program (DEP) is associated with lower attrition rates, perhaps owing to the DEP counteracting the effects of impulsiveness (Antel, Hosek, \& Peterson, 1987). Data suggest an interactive effect between personal characteristics and organizational factors. For example, individuals with higher education levels and AFQT scores who are college bound tend to complete a term (Black \& Fraker, 1984; Boesel \& Johnson, 1984), most likely to capitalize on education benefits. Youth who enlist on the buddy plan are also more likely to "make it" as are women in occupations with a higher and more supportive "female mix." Organizational factors have been shown to contribute to the typically lower attrition rates for graduates compared to nongraduates in that, generally, graduates may be better matched to their jobs than nongraduates. However, Buddin (1988) suggested that when there are more high school graduates in an entering cohort, they are less well matched to the job. The more graduates there are, the more likely they are to be subject to less attractive assignments that may have been plugged previously with demand-constrained nongraduates.

Unlike factors associated with early attrition, attrition later in the term tends to hinge on family and social problems as well as job-related factors (Goodstadt \& Glickman, 1975; Greenberg, et al., 1972; Youngblood, Meglino, Mobley, \& Moore, 1980). Though job characteristics such as combat affiliation (Ward \& Tan, 1985), low complexity or mental challenge, and unpleasant working conditions (Rosenthal \& Laurence, 1988) have been implicated as contributors to attrition, job satisfaction has been found to be only slightly (Knapp, 1993; Knapp, Carter, McCloy, \& DiFazio, 1994; Knapp, McCloy, \& DiFazio, 1993), if at all (Buddin, 1984) predictive. Job satisfaction's poor showing is confounded with time of attrition. That is, a substantial proportion of recruits separate early before actually getting to the job. For later attrition, job satisfaction is implicated. The finding that job satisfaction is related, as well as the findings that individual variables interact with situational variables, suggests that better matches between individuals and organizational and job characteristics are worthwhile attrition interventions.

Another organizational factor that is important to consider is management and/or administrative policies. There is evidence that attrition is managed to some extent at various levels. This evidence takes the form of Service differences, post (installation) differences within Service, a failure to find a decrease in attrition in the field despite an increase in trainee discharge rates, and the fact that attrition can be lowered if directed 
(Bauer, Miller, Dodd, \& Segal, 1975; Buddin, 1984; Buddin, 1988; Department of the Army, 1984; General Accounting Office, 1980). Post differences are partially attributable to variations in leadership experience and styles among drill instructors. For example, the Army found evidence that training units led by E-6s from the combat arms, who were less competitive, more nurturing, and did not front load stress had lower attrition. The recruiting environment and the availability of replacements also directly affects attrition (Buddin, 1988). When supply is high, so too is attrition. Installation, recruiting market, and seasonal effects also support the existence of a "Pygmalion" or self-fulfilling prophecy effect, overall and perhaps more so for certain at-risk groups such as nongraduates (see Goodstadt \& Glickman, 1975; Sarason, Novaco, Robinson, \& Cook, 1981). While administrative decisions would benefit from firmer guidelines for separation and fine tuning, early, quick separations should not be precluded. After all, such policies may save training costs and efficiently eliminate perpetual "trouble makers." Further, because attrition is not expected to be absent, a constant rate may be desirable because it can be anticipated when formulating accession goals. Such issues call for attrition standards and the application of a cost/effectiveness framework. The issue of the management of attrition is a pivotal one. The extent to which it is managed is not precisely known. An understanding of the policy control, explicit and implicit, exerted over attrition is the key to the attrition problem. Without knowing how and the degree to which attrition is managed, attempts to reduce attrition are hampered.

One organizational intervention that has showed moderate success is the realistic job preview (RJP). The RJP attempts to provide accurate information about the organization and the job to the applicant, thereby maximizing the mutual choice between the organization and the candidate. Past research has shown at least a modest relationship between the employees' lack of realistic information about the job and organization and turnover (Wanous, 1977). In a review of six field studies, Wanous found, in all cases, that the RJP increased job survival rates, although some of the improvements were not statistically significant.

There are a few instances where RJPs have been studied in the military context. A study by Meglino, Youngblood, and Mobley (1982), of Marine Corp recruits involved the presentation of an RJP film. At six and twelve months, the group that viewed the film had significantly more survival days and better performance than the control group. A similar study by Githens and Zalinski (1983) had Marine Corp platoons assigned to different experimental groups who viewed either one or two training films presenting a realistic job preview and/or stress-coping skills. The results of this study showed that neither film was effective in reducing attrition when compared to the control group. Unfortunately, RJP studies are rare and the existing ones show inconsistent results.

It can be argued that RJPs have not been given a proper chance to combat attrition. When an RJP is given--before or after the employment decision--seems to make a difference. For instance, when an RJP is given after the commitment decision has been made, it amounts to more of an orientation or a modeling of strategies than a 
self-selection mechanism. Providing the job candidate the opportunity to self-select would be an even greater means through which to lower attrition rates possibly by inoculating the applicant or creating a situation in which attrition would create cognitive dissonance (Wanous, 1977). There is research lending support to the idea that RJPs allow applicants to judge their match with that of the needs and demands of the organization. In addition to RJP timing, their construction and delivery are also worthy of study.

RJPs have potential as an organizational strategy to counter attrition. Although RJPs have been only modestly successful, the verdict is still out as to their success. In addition, they are relatively simple to administer and are relatively low in cost compared to many other organizational strategies. A word of caution, however: one must be careful to ensure that realistic, situation-specific scenarios are presented in the RJP and that the intervention is addressed to the appropriate target audience (e.g.,potential enlistees).

Potentially useful variants of the RJP for countering unrealistic expectations of military life that have been noted to occur even before a recruit is on the job are to present a realistic preview of the environment and behavior expected (as well as explaining their necessity). Such up-front counseling may better explain and prepare a would-be recruit for the physical rigors, the constant training, and the discipline exacted.

Finally, aside from the potential value of information to prevent unrealistic expectations, counseling after the fact may also be useful in ameliorating the conditions leading to attrition. Apparently, counseling is the exception rather than the rule and the adequacy of current counseling is open to debate (Department of the Army, 1984).

As with screening on the basis of individual characteristics, some organizational interventions may not be practical and none will eliminate attrition in its entirety. Turnover among persons in the military's targeted age group for accession is bound to be high (General Accounting Office, 1980; Goodstadt \& Glickman, 1975; Waite, \& Berryman, 1985). However, though there is evidence that the military experiences less turnover than the civilian sector, whether justified or not, recruiting, outfitting, and training costs are cited as reasons why attrition should be held at bay.

Measuring Attrition. Researchers who attempt to quantify and predict attrition must deal with various properties of this criterion that constrain conventional statistical approaches. First, is the dichotomous nature of this criterion. Furthermore, the typical correlation or validity coefficient is restricted in range because attrition has a relatively low base rate and the split between stayers and leavers is uneven; the former outnumbering the latter. The earlier the criterion is measured, the more divergent the split. In a nutshell, it's hard to predict this criterion very well. 
Multivariate approaches to predicting attrition have been found to be inadequate as well. Because attrition is an "event" that is not normally distributed, there is a need for alternatives to Ordinary Least Squares or even Logistic regression for describing and predicting this criterion. Such an alternative exists in event history analysis (see McCloy, DiFazio, \& Carter, 1993). This measurement technique examines the role of time and can accommodate moderating variables.

Event history analysis allows modelling of whether or not an event (separation) occurs, and if so, when it occurs. Event history analysis evaluates the interval between two events -- enlistment and separation. This evaluation is complicated by the presence of censored observations--observations for which the event of interest (separation) does not occur during the observation period. Further, the actual period of observation may not be the same for all people. That is, not everyone separates from the military, and not everyone enlists on the same day.

In many ways, event history models share much in common with traditional analytic strategies. For example, event history analyses generate both descriptive and inferential statistical information. Group differences in event occurrence can be tested, and statistical models relating independent variables to event occurrence can be developed. However, event history models incorporate time--a variable shown to be salient for attrition. Time can be measured discretely (e.g., months) or continuously. The inclusion of time allows the modeling of both short and long criteria (i.e., early and late attrition) which make a difference in uncovering significant relationships. For example, Smith and Walker (1986) found that women tend to separate earlier than men.

Stratifying a population into subgroups makes it possible to estimate an event history model for each subdivision of the population. Once this is done it may be of interest to compare the subgroups (e.g., high school diploma graduates versus non-high school diploma graduates) to see if the event behavior differs by subgroup.

The descriptive information provided by subgroup event history analysis can be used for applicant screening. In addition, inferential statistical approaches have been used to develop predictive models of attrition.

In short, these methods provide a powerful set of tools for answering a variety of questions about the "whether" and "when" of military attrition. Event history methods offer many advantages over traditional approaches for studying military attrition. They provide the longitudinal perspective necessary to model the complex paths that recruits take through the military. They can reflect dynamic and changing decision-making reality far better than static end-product models that emphasize the occurrence of single transition at a particular point in time. And models that describe the risks of termination can include information about many predictors simultaneously. No longer must those who have yet to separate be treated in an ad hoc fashion; they can be included for as long as there are data to describe their behavior. 
Event history analysis is an important tool that can help explicate the phenomenon of attrition. It need not be the only tool. In particular, another analytic strategy that should be considered when searching for indirect effects on attrition is path analysis. That is, certain variables (e.g., demographics) may be related to attrition indirectly through organizational variables (e.g., supportive environment).

\section{Concluding Notes}

An important prescription for solving the problem of first-term enlisted attrition is understanding the nature of the criterion/criteria. It is important to understand the reasons for, behaviors leading up to, and timing and categorization of attrition. Though the diverse codes for attrition may be incidences of the same construct--organizational delinquency--proof is needed. Furthermore, there may be differential validity for predicting behavioral and medical attrition as well as attrition during basic, during technical training, and on the job that is currently masked. Different approaches are needed to tackle different forms of attrition.

Critical incidents gathered through interviews or focus groups with recruits (including attriters) and supervisors across different units and locations (and at different points) are warranted to clarify the factors related to attrition and lead to the development of more objective, standardized, reliable, and valid separation codes and procedures. The development and operational use of behaviorally anchored rating scales (BARS) for attrition are worth investigation. Exemplars of behaviors warranting a soldier's separation .could be elicited from experts and used as guidelines in determining whether separation is in order. Currently, a consistent percentage of recruits are separated. The potential problem with this is that the worst third in one cohort may not be the worst third in another. There are no fixed performance standards, particularly with regard to attrition. Without first tackling the management of attrition, attempts to reduce attrition will be futile.

A related research endeavor would be the conduct of policy capturing studies to uncover attrition salient behaviors of would-be separated soldiers. Such a technique could be used among supervisory personnel not only to pinpoint circumstances leading to counseling, disciplinary actions, and attrition (including type categorization) but also provide data on personal dimensions (e.g., diploma status, race, gender) that are part of or bias the decision making process. Similarly, research on the criterion end of the equation may lead to the establishment of acceptable or expected ranges of attrition.

Though personal factors and their relationship to attrition have been studied extensively, such studies have been conducted, more or less, on a single factor basis and therefore are misleading. For example, studies by race that do not include aptitude and education level show different findings from studies with such controls. Similarly, failure to account for gender may complicate conclusions. Incredulous assertions by public 
watchdogs that attrition is high despite the increase in diploma graduates among accessions, fail to consider other variables related to attrition. It is important to track attrition and monitor the interrelationships among individual characteristics. Such tracking and monitoring may lead to a better understanding of why attrition rates remain steady while "quality" rises. It would also behoove the Army to better understand why certain personal characteristics are related to attrition. For example, if the higher attrition rates for women are partially a function of the female mix and corresponding support or lack of isolation in MOS, then such higher rates may be only temporary. A valuable measurement tool that should be considered in such attrition studies is discrete event history or survival analysis. The timing and pattern across numerous variables can be taken into account by this technique.

The extant (yet short) research base related to organizational correlates suggests the need to counteract recruits' unrealistic expectations. Realistic previews of military life and work and behaviors that are extolled and contraindicated warrant development. Recruits should be apprised of the need for regimentation, rigorous physical training, and discipline. Also, given that recruits are thought to undervalue their compensation, it would be wise to counsel them regarding its true value and its relationship to civilian alternatives. Likewise, counseling in pivotal areas should be developed and utilized to foster rehabilitative efforts. Though it would be impossible to avoid all stressful working conditions and aspects of Army life (e.g., separations from family), a look at psychological rewards, amenities, conveniences, and other incentives is in order. After all, educational incentives apparently work toward holding the college bound through an enlistment term. Keep in mind that increased counseling will demand resources also, including an increased load on drill instructors and other supervisors.

The role of recruiting in attrition is a fruitful line of inquiry. Recruiting may contribute to unrealistic expectations. However, realistic previews of military life may not be well received by the recruiting community as they tend to reduce the pool of applicants through self-selection or otherwise impede recruiting. Recruiters could be credited with an enlistment if, and only if, the recruit made it through technical training or at least basic training. The costs and benefits of such an approach along with recruiter contingencies for attrition are indicated. Adjustments to recruiters' goals might have to accompany rewards for a recruit making it through training, for example.

The literature hints that the merging of individual and organizational remedies could foster first term completion. That is, while biodata and temperament have not been implemented as a selection screen owing to potential stability and compromise problems, such problems may not surface if these instruments are used for classification instead. The ABLE and Army Vocational Interest Career Examination (AVOICE) may make an important, non-cognitive, contribution to attrition if used to secure better matches between individuals and jobs or at least to steer recruits away from particularly poor job choices. Of course even if all these suggestions panned out and numerous measures were adopted, attrition would not cease to exist; nor should it, since not all 
attrition is bad. And planning for attrition is wise. However, it is important to understand the factors impinging on attrition. Understanding leads to control and the lack of understanding is perhaps the "problem" with attrition. Though the military may take consolation in the fact that selection, contracting, socialization, and so forth make for lower turnover than in the civilian sector, reducing attrition by a few percentage points may save substantial dollars and better serve the individual and the institution.

In short, the best bets toward solving the attrition problem are: to determine the extent of management/policy control at various levels and set guidelines that are appropriate; and enhance the match between the individual and the organization through classification based on biodata/temperament as well as realistic previews of the job, the environment, and the behavior. Finally, concern over attrition by outside parties (e.g., Congress) is not likely to subside. The Army would be in a better position to answer continuing concerns if the causes and codes were tracked by personal characteristics, and their interactions were understood. The Army could then account for and explain attrition levels and tradeoffs between attrition and other personnel policies. 


\section{References}

Allison, P. D. (1984). Event history analysis: Regression for longitudinal event data (Sage University paper series on quantitative applications in the social. sciences, Number 07-046). Beverly Hills, CA: Sage.

Antel, J., Hosek, J.R., \& Peterson, C.E. (1987, June). Military enlistment and attrition: An analysis of decision reversal (R-3510-FMP). Santa Monica, CA: RAND.

Bauer, R.G., Miller, T.J., Dodd, M.I.,\& Segal, D.R. (1975, November). Evolution of early enlistment failures under the U.S. Army trainee discharge program. Arlington, VA: U.S. Army Research Institute.

Bell, D.B. (1979, October). Characteristics of Army deserters in the DOD special discharge review program (Research Report 1229). Arlington, VA: U.S. Army Research Institute.

Beusse, W.E. (1977, May). Factors related to the incidence of disciplinary actions among enlisted personnel (AFHRL-TR-75-21). Lackland Air Force Base, TX: Personnel Research Division.

Black, M. \& Fraker, T. (1984, January). An analysis of the success of high school graduates in the military. Washington, D.C.: U.S. Department of Education.

Boesel, D., \& Johnson, K. (1984). Why service members leave the military: Review of the literature and analysis. Arlington, VA: Defense Manpower Data Center.

Buddin, R. (1984). Analysis of early military attrition behavior (R-3069-MIL). Santa Monica, CA: Rand.

Buddin, R. (1988). Trends in attrition of high-quality military recruits (R-3539-FMP). Santa Monica, CA: Rand.

Campbell, J.P., \& Zook, L.M. (Eds.). Improving the selection, classification, and utilization of Army enlisted personnel: Final report on Project A (ARI Research Report 1597). Alexandria, VA: U.S. Army Research Institute for the Behavioral and Social Sciences. (AD A242 921)

Cheatham, C.W. (1978, June). The high school graduate, an indicator of a quality Marine? Fort Leavenworth, KS: U.S. Army Command and General Staff College.

Cooke, T.W., \& Quester, A.O. (1988, June). Who stays and who leaves? Identifying successful Navy recruits (CRM 88-75). Alexandria, VA: Center for Naval Analyses. 
Department of the Army. (1984, December). A review and analysis of the Army's Trainee Discharge Program. Fort Monroe, VA: United States Army Training and Doctrine Command.

Department of Defense. (1981, December). Implementation of new Armed Services Vocational Aptitude Battery and actions to improve the enlistment standards process. Report to the House and Senate Committees on Armed Services. Washington, DC: Office of the Assistant Secretary of Defense (Manpower, Reserve Affairs, and Logistics).

Dempsey, J.R., Laurence, J.H., Waters, B.K., \& McBride, J. (1991, November). Proposed methodology for the development of a compensatory screening model for attrition (FR-PRD-91-17). Alexandria, VA: Human Resources Research Organization.

Dempsey, J.R., \& Waters, B.K. (1989, November). Interservice separation codes: A dilemma for attrition studies. Paper presented at the 31st Annual Conference of the Military Testing Association, San Antonio, TX. Alexandria, VA: Human Resources Research Organization.

Edwards, J.E., McBride, J.R., Waters, B.K., \& Laurence, J.H. (1993). Adaptability screening: Conclusions and implications. In T. Trent, \& J.H. Laurence, (Eds.), Adaptability screening for the Armed Forces. Washington, D.C.: Office of the Secretary of Defense.

Eitelberg, M.S. (1993, September). The All-Volunteer force after twenty years. Paperpresented at a Conference Commemorating the 20th Anniversary of the AllVolunteer Force, Annapolis, MD. Monterey, CA: Naval Postgraduate School.

Elster, R.S., \& Flyer, E.S. (1982, April). A study of relationships between educational credentials and military performance criteria (NPS54-82-008). Monterey, CA: Naval Postgraduate School.

Fernandez, R.L. (1985). Setting enlistment standards and matching recruits to jobs using job performance criteria (R-3067-MIL). Santa Monica, CA: RAND.

Finstuen, K., \& Alley, W.E. (1983). Occupational correlates of first term enlisted tenure (AFHRL-TR-82-36). Brooks, Air Force Base, TX: Manpower and Personnel Research Division, Air Force Human Resources Laboratory.

Flyer, E.S. (1963, June). Prediction of unsuitability among first-term airmen from aptitude indexes, high school reference data, and basic training evaluations (PRL-TDR-63-17). Lackland Air Force Base, TX: Personnel Research Laboratory. 
Flyer, E.S., \& Elster, R.S. (1983, June). First term attrition among non-prior service enlisted personnel: Loss probabilities based on selected entry level procedures. Monterey, CA: Naval Postgraduate School.

Foch, C., \& King, N. (1977, June). Gatekeepers: First term enlisted attrition policies and practices. In H.W. Sinaiko (Ed.), First term enlisted attrition, Volume I: Papers (TR-3). Arlington, VA: Office of Naval Research.

General Accounting Office. (1979, February). High cost of military attrition can be reduced (FPCD-79-28). Report to the Secretary of Defense. Washington, DC: Author.

General Accounting Office. (1980, February). Attrition in the military -- An issue needing management attention (FPCD-80-10). Report to the Congress. Washington, DC: Author.

General Accounting Office. (1994). Military recruiting:Innovative approaches needed (Draft Report). Washington, DC: Author.

Githens, W.H., \& Zalinski, J. (1983, May). Marine Corps recruit training attrition: The effect of realistic job preview and stress-coping films (NPRDC TR 83-18). San Diego, CA: Navy Personnel Research and Development Center.

Goodstadt, B.E., \& Glickman, A.S. (1975, November). The current status of enlisted attrition in the U.S. Navy and in the U.S. Marine Corps and the search for remedies. Washington, D.C: American Institutes of Research.

Goodstadt, B.E., \& Yedlin, N.C. (1980, June). First-tour attrition: Implications for policy and research (Research Report No. 1246). Alexandria, VA: U.S. Army Research Institute.

Greenberg, M.S., Murphy, J., \& McConeghy, G. (1977, September). Exploratory development research of USN and USMC personnel: Phase I factors affecting attrition (Final Report). Arlington, VA: Office of Naval Research.

Hand, H.H., Griffeth, R.W., \& Mobley, W.H. (1977, December). Military enlistment, reenlistment and withdrawal research: A critical review of the literature (TR-3). Arlington, VA: Office of Naval Research.

Hogan, J. \& Hogan, R. (1989). How to measure employee reliability. Journal of Applied Psychology, 74(2), 273-279.

Kantor, J.E., \& Quinn, N. (1975, December). Comparison of performance and career progression of high school graduates and non-graduates in the Air Force (AFHRL- 
TR-75-73). Brooks Air Force Base, TX: Personnel Research Division.

Klein, S., Hawes-Dawson, J., \& Martin, T. (1991). Why recruits separate early (R-3980FMP). Santa Monica, CA: RAND.

Klein, S., \& Martin, T. (1991, January). Forecasting first term attrition (Working Draft). Santa Monica, CA: RAND.

Knapp, D.J. (1993, August). Alternative conceptualizations of turnover. Paper presented at the 101st Annual Convention of the American Psychological Association, Toronto, Canada.

Knapp, D.J., Carter, G.W., McCloy, R.A., \& DiFazio, A.S. (1994, July). The role of job satisfaction in performance, attrition, and reenlistment. In J.P. Campbell \& L. M. Zook, (Eds.), Building and retaining the career force: New procedures for accessing and assigning Army enlisted personnel. Alexandria, VA: U.S. Army Research Institute.

Knapp, D.J., McCloy, R.A., \& DiFazio, A.S. (1993, August). Prediction of military turnover using intentions, satisfaction, and performance. Paper presented at the 101st Annual Convention of the American Psychological Association, Toronto, Canada.

Laurence, J.H. (1984, February). Education standards for military enlistment and the search for successful recruits (FR-PRD-84-4). Alexandria, VA: Human Resources Research Organization.

Laurence, J.H. (1987, September). Military enlistment policy and education credentials: Evaluation and improvement (FR-PRD-87-33). Alexandria, VA: Human Resources Research Organization.

Laurence, J.H., \& Gribben, M.A. (1990, July). Military selection strategies (FR-PRD-9015). Alexandria, VA: Human Resources Research Organization.

Laurence, J.H., \& Waters, B. (1993). Biodata: What's it all about? In T. Trent, \& J.H. Laurence, (Eds.), Adaptability screening for the Armed Forces. Washington, D.C.: Office of the Secretary of Defense.

Lockman, R.F. (1975, May). Chief of Naval Personnel briefing on enlisted tracking study. Alexandria, VA: Center for Naval Analyses.

Matthews, W.T. (1977, June). Quality of Marines: Pre-enlistment screening based on predicted performance (CNS 1100). Arlington, VA: Center for Naval Analyses. 
McCloy, R.A., DiFazio, A.S., \& Carter, G.W. (1993, August). Prediction of first-term military attrition using pre-enlistment predictors. Paper presented at the 101st Annual Convention of the American Psychological Association, Toronto, Canada.

Means, B. (1983, November). Moral standards for military enlistment: Screening procedures and impact (FR-PRD-83-26). Alexandria, VA: Human Resources Research Organization.

Meglino, B.M., Youngblood, S.A.,\& Mobley, W.H. (1982, August). Research on Marine Corps enlisted personnel attrition (TR-14). Arlington, VA: Office of Naval Research.

Mobley, W.H., Hand, H.H., Baker, R.L., \& Meglino, B.M. (1978, February). An analysis of predictors of recruit training attrition in the U.S. Marine Corps (TR-5). Arlington, VA: Office of Naval Research.

Novaco, R.W., Sarason, I.G., Cook, T.M., Robinson, G.L., \& Cunningham, F.J. (1979, November). Psychological and organizational factors related to attrition and performance in Marine Corps recruit training (AR-001). Arlington, VA: Office of Naval Research.

Olson, M.S., \& Stumpf, S.S. (1978, September). Pregnancy in the Navy: Impact on absenteeism, attrition, and workgroup morale (NPRDC TR 78-15). San Diego, CA: Navy Personnel Research and Development Center.

Plag, J. (1971). A decade of research in prediction of Naval enlistee effectiveness. Psychopharmacology Bulletin, Vol. 7(7).

Rosenthal, D.B., \& Laurence, J.H. (1988, June). Job characteristics and military attrition (FR-PRD-88-11). Alexandria, VA: Human Resources Research Organization.

Sarason, I.G., Novaco, R.W., Robinson, G.L., \& Cook, T.M. (1981, April). Recruit attrition and the training unit environment (AR-004). Arlington, VA: Office of Naval Research.

Segal, D.R., (1981, March). Military organization and personnel accession: What changed with the $A V F$... and what didn't(MS-3). College Park, MD: Center for Philosophy and Public Policy, University of Maryland.

Seibold, G. (1981, October). Attrition: Causality, explanation, and level of analysis. Paper presented at the 23rd Annual Conference of the Military Testing Association, Arlington, VA. Alexandria, VA: U.S. Army Research Institute. Personnel Utilization Technical Area. 
Sheridan, J.A., \& Monaghan, J.O. (1980, August). Navy attrition and turnover in private industry: Concepts, measurement, and management. Arlington, VA: Office of Naval Research.

Sinaiko, H.W., Chatelier, P.R., Cook, C.A., Hosek, J.R., \& Sicilia, G.T. (1981, October). Military personnel attrition and retention research in progress (TR-10). Arlington, VA: Office of Naval Research.

Sinaiko, H.W., \& Scheflen, K.C. (1980, October). Attrition in the Armed Services of Canada, the UK, and the U.S.:A collaborative study. TTCP Technical Panel UTP3.

Sinaiko, H.W., \& Scheflen, K.C. (1982, December). Correlates of first term attrition: $A$ comparison across TTCP Nations. TTCP Technical Panel UTP-3.

Singer, J. D., \& Willett, J. B. (1991). Modeling the days of our lives: Using survival analysis when designing and analyzing longitudinal studies of duration and the timing of events. Psychological Bulletin, 110(2), 268-290.

Smith, J.V., \& Kendall, W.A. (1980, June). Personal, situational, and organizational determinants of Navy enlisted attrition. Unpublished master's thesis. Monterey, CA: Naval Postgraduate School.

Smith, E.P., \& Walker, C.B. (1986). Short versus long term tenure as a criterion for validating biodata. Paper presented at the 28th Annual Convention of the Military Testing Association, Mystic, CT.

Stolzenberg, R.M., \& Winkler, J.D. (1983, May). Voluntary terminations from military service (R-211-MIL). Santa Monica, CA: Rand.

Waite, L.J., \& Berryman, S.E. (1985, March). Women in nontraditional occupations: Choice and turnover (R-3106-FF). Santa Monica, CA: Rand.

Walker, C.B., White, L.A., \& Schroyer, C. (1989, August). Implementing the U.S. Army's Assessment of Background and Life Experiences (ABLE). Paper presented at the 97th Annual Convention of the American Psychological Association, New Orleans, LA.

Wanous, J.P. (1977). Organizational entry: Newcomers moving from outside to inside. Psychological Bulletin, 84(4), 601-618.

Ward, M.P., \& Tan, H.W. (1985, February). The retention of high-quality personnel in the U.S. Armed Forces (R-3117-MIL). Santa Monica, CA: Rand. 
White, L. A., Nord, R.D., Mael, F. A., \& Young, M.C., (1993). The Assessment of Background and Life Experiences (ABLE). In T. Trent, \& J.H. Laurence, (Eds.). Adaptability Screening for the Armed Forces. Washington, D.C.: Office of the Secretary of Defense.

Youngblood, S.A., Meglino, B.M., Mobley, W.H., \& Moore, D.P. (1980, January). $A$ cross sectional analysis and generalizability implications of a military attrition model (TR-10). Arlington, VA: Office of Naval Research.

Youngblood, S.A., Laughlin, J.E., Mobley, W.H., \& Meglino, B.M. (1980, January). A longitudinal analyses of military recruit attrition: The first 25 months (TR-11). Arlington, VA: Office of Naval Research. 